\title{
HUBUNGAN STATUS GIZI (INDIKATOR IMT) TERHADAP KEJADIAN METABOLIC SYNDROME DI PONDOK PESANTREN AL-HIDAYAH, KABUPATEN NGAWI 2018
}

\author{
Choirotussanijah, Hotimah \\ Program Studi S1 Pendidikan Dokter, Fakultas Kedokteran \\ Universitas Nahdlatul Ulama Surabaya \\ e-mail: hotimah.dr@unusa.ac.id
}

\begin{abstract}
Metabolic syndrome is a complex metabolic disorder that is caused by obesity. Body mass index could be simple indicator and very recommended for assessed nutritional state. This study aim to found correlation between nutritional state using BMI to total metabolic syndrome in Pesantren Al Hidayah Kabupaten Ngawi, East Java. Beside, this study is expected could give information for medical officer, especially in Kabupaten Ngawi area as a strategy to prevent metabolic disorder and as new knowledge for peoples in Pesantren Al Hidayah area. Study design using analytic descriptive. Study run in Juni-July 2018 with participants came from population in Pesantren area. We get data about abdomen circumference, body weigh and height, blood pressure, and blood glucose. From 72 participants, 3 participants is suspected suffer from metabolic syndrome, while 61 other was not. The results did not show significancy in statistic. However, the others study showed significant result for correlation nutritional state and body mass index.
\end{abstract}

Keywords: Nutritional Status, Metabolic Syndrome, Boarding School

\begin{abstract}
ABSTRAK
Sindrom Metabolik (SM) merupakan kelainan metabolik kompleks yang diakibatkan oleh peningkatan obesitas. Indeks masa tubuh merupakan indikator sederhana dan direkomendasikan sebagai indikator untuk menentukan status gizi. Tujuan dari penelitian ini adalah untuk mengetahui hubungan status gizi dengan indikator IMT terhadap prediksi sindroma metabolik di pesantren AlHidayah kabupaten Ngawi. Selain itu, hasil penelitian ini diharapkan dapat dipergunakan sebagai bahan informasi bagi tenaga medis, khusus nya di wilayah kabupaten Ngawi sebagai acuan strategi pencegahan penyakit metabolik di wilayah Ngawi serta dapat memberikan pengetahuan tambahan bagi masyarakat disekitar pesantren Al-Hidayah dalam upaya pencegahan dan pengobatan pada penyakit metabolik. Desain penelitian yang digunakan adalah penelitian deskriptif analitik. Penelitian dilaksanakan pada saat baksos di pondok pesantren Al-Hidayah, Ngawi, Jawa Timur. Penelitian dilaksanakan pada bulan Juni-Juli 2018 dengan populasi penelitian adalah semua peserta baksos di pondok pesantren Al-Hidayah yang hadir. Data peserta yang dikumpulkan adalah lingkar perut, berat badan dan tinggi badan, tekanan darah, gula darah acak. Dari 72 peserta, gejala sindroma metabolik terjadi pada 3 peserta, sedangkan 61 peserta lainnya tidak didapatkan sindroma metabolik. Hal ini menunjukkan hasil yang tidak signifikan pada uji statistik. Selain itu, beberapa penelitian dengan jumlah subjek penelitian yang berjumlah besar, menunjukkan signifikansi antara
\end{abstract}


parameter-parameter yang diukur dalam penelitian ini sesuai dengan munculnya sindroma metabolik.

Kata kunci: Status Gizi, Sindrom Metabolik, Pondok Pesantren

\section{PENDAHULUAN}

World Health Organization (WHO) 2013 mengemukakan bahwa non-communicable disease (NCDs) merupakan tantangan kesehatan terbesar pada abad 21. Dari seluruh angka morbiditas NCDs, jumlah cardiovascular disease (CVD) merupakan yang terbesar yaitu 17,3 juta jiwa/ tahun. Selain itu, berkaitan dengan diabetes, pada sebagian penderita diabetes tipe dua atau intoleransi glukosa, didapatkan serangkaian faktor risiko yang muncul bersamaan dengan faktor risiko CVD. Fenomena ini disebut dengan kejadian sindrom metabolik.

Sindrom Metabolik (SM) merupakan kelainan metabolik kompleks yang diakibatkan oleh peningkatan obesitas. ${ }^{1}$ Perdebatan tentang definisi ini terjadi seiring dengan hasil penelitian yang terus berkembang, namun seluruh kelompok studi tersebut setuju bahwa obesitas, resistensi insulin, dislipidemia dan hipertensi merupakan komponen utama SM. ${ }^{2}$ Perdebatan tentang definisi ini terjadi seiring dengan hasil penelitian yang terus berkembang, namun seluruh kelompok studi tersebut setuju bahwa obesitas, resistensi insulin, dislipidemia dan hipertensi merupakan komponen utama SM. $^{2}$ Prevalensi metabolic sindrom secara global berbeda tergantung pada geografis dan faktor sosiodemografi, serta kriteria diagnosis yang digunakan. Pada hasil survey oleh National Cholesterol Education Program Adult Treatment Panel III di memperkirakan bahwa $35 \%$ orang dewasa di Amerika Serikat, dan sebanyak $50 \%$ dari populasi di atas 60, memiliki diagnosis MetS (30,3\% pada pria dan $35,6 \%$ pada wanita), ${ }^{3}$ dengan tren terkini menunjukkan bahwa secara keseluruhan prevalensi dan penurunan prevalensi pada wanita. $^{4}$

Obesitas dinyatakan sebagai salah satu dari sepuluh masalah kesehatan utama di dunia dan kelima teratas di negara berkembang. Obesitas dapat terjadi terutama akibat peningkatan asupan makanan dan penurunan aktifitas fisik. Berbagai peneliti menemukan faktor risiko obesitas yang lain seperti konsumsi makanan, alkohol, riwayat merokok dan aktifitas fisik. ${ }^{5}$

Indeks masa tubuh merupakan indikator sederhana dan direkomendasikan sebagai indicator untuk menentukan status gizi. ${ }^{6}$ Penelitian sebelumnya menyatakan bahwa terdapat hubungan bermakna antara IMT dengan kejadian DM tipe 2, serata meningkatnya obesitas menyebabkan terjadinya komplikasi. 


\section{METODE PENELITIAN}

Desain penelitian yang digunakan adalah penelitian deskriptif analitik dengan pendekatan cross sectional study. ${ }^{7,8}$ Penelitian dilaksanakan pada saat baksos di pondok pesantren AlHidayah, Ngawi, Jawa Timur. Penelitian di laksanakan pada bulan Juni-Juli 2018. Populasi penelitian adalah semua peserta baksos di pondok pesantren Al-Hidayah yang hadir.

Data yang dikumpulkan adalah lingkar perut, berat badan dan tinggi badan, tekanan darah, data gula darah acak. Teknik analisis yang digunakan adalah uji statistic Chi square. Derajat kepercayaan yang digunakan adalah 95\%. Jika $\mathrm{p}$ value lebih kecil dari a $(\mathrm{P}<0.05)$ maka terdapat hubungan bermaknas dari kedua variable yang diteliti. Apabila p-value lebih besar dari a $(\mathrm{P}>0.05)$ maka tidak terdapat hubungan yang bermakna antara kedua variable yang diteliti.

\section{HASIL DAN PEMBAHASAN}

\section{Hasil}

Distribusi responden berdasarkan jenis kelamin

Berdasarkan data yang diperoleh, di dapatkan distribusi responden berdasarkan jenis kelamin. Hasil distribusi laki-laki sebanyak $31,6 \%$ dan perempuan 66,3\%. Sebaran responden terhadap jenis kelamin tidak merata.

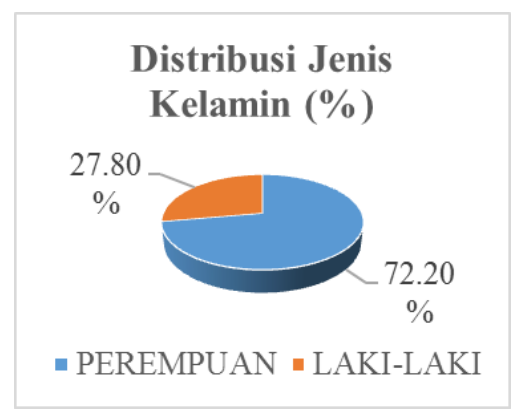

Gambar 1. Distribusi responden berdasarkan jenis kelamin

Distribusi responden berdasarkan Body mass Index (BMI)

Data IMT secara keseluruhan dari total responden didapatkan sebesar $6,94 \%$ berstatus kurus, normal sebesar 48,61\%, gemuk sebesar $29.17 \%$ dan obesitas didapatkan sebesar $15,28 \%$. Status ukuran IMT pada laki-laki dan perempuan berbeda. Dari data responden, didapatkan distribusi responden dengan BMI pada laki-laki dan perempuan berbeda. Pada respondens laki-laki BMI normal didapatkan sebanyak $70 \%$,

Distribusi IMT Keseluruhan

(\%)

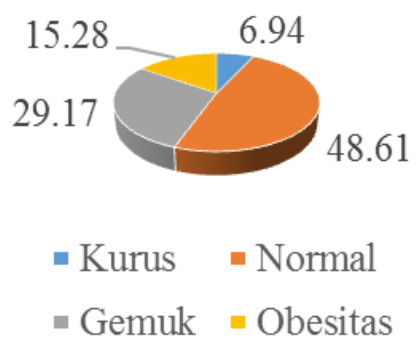

Gambar 2. Distribusi responden berdasarkan Body mass Index (BMI) 
BMI dengan obesitas sebanyak 10\%. Sedang kan pada responden perempuan didaptkan BMI normal sebanyak $40,38 \%$, gemuk sebanyak $38,46 \%$ dan dengan status BMI obesitas sebanyak $17,31 \%$.

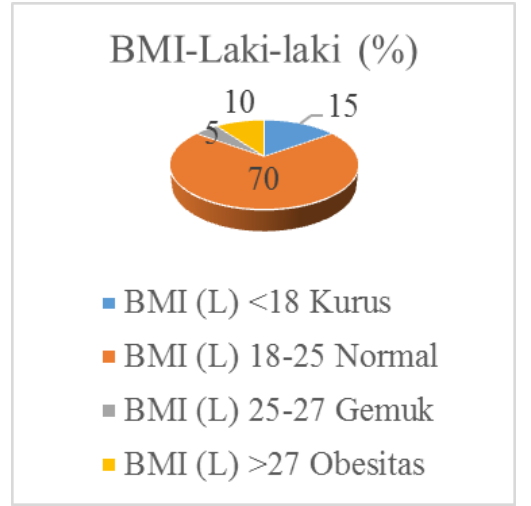

Gambar 3. Distribusi responden laki-laki berdasarkan Body mass Index (BMI)

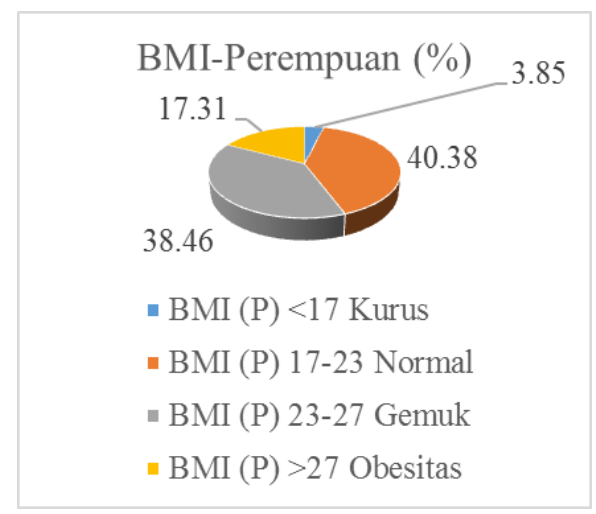

Gambar 4. Distribusi responden perempuan berdasarkan Body mass Index (BMI)

Distribusi responden berdasarkan kadar gula darah acak (GDA)

Berdasarkan data yang diperoleh didapatan distribusi responden dengan kadar glukosa darah acak yang <200 mg/dl sebanyak $72,2 \%$ dan distribusi responden dengan GDA $>200 \mathrm{mg} / \mathrm{dl}$ sebanyak $9,68 \%$.

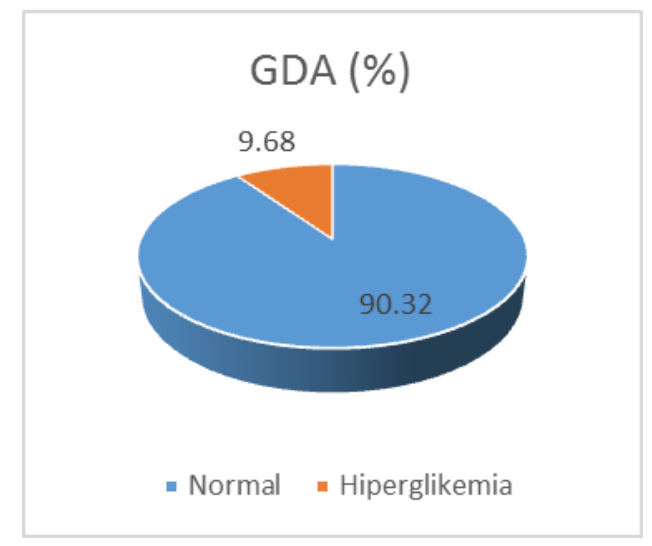

Gambar 5. Distribusi responden berdasarkan kadar gula darah acak (GDA)

\section{Insiden sindroma metabolik berdasarka IMT}

Dari data yang diperoleh, didapatkan bahwa dari total 73 responden dengan IMT yang di golongkan obesitas 3 orang yang mengalami sindrom metabolik. Sedangkan kriteria IMT yang tergolong normal dan gemuk tidak didapatkan responden yang mengalami metabolic sindrom. Berdasarkan data analisis tersebut didapatkan hasil nilai $\mathrm{p}=0.204$. nilai $\mathrm{p}$ tersebut kurang dari nilai $\alpha(0.05)$. Dapat disimpulkan bahwa.

\begin{tabular}{lccccc}
\hline & \multicolumn{2}{c}{ Sindroma } & & & \\
& metabolik & Total & $\begin{array}{c}\text { Chi- } \\
\text { square }\end{array}$ & Value \\
\hline Kidak & Ya & & & \\
Normal & 5 & 0 & 5 & & \\
Gemuk & 21 & 0 & 35 & 0,204 & 1,75 \\
Obesitas & 9 & 3 & 21 & & \\
\hline
\end{tabular}

\section{Pembahasan}

Berdasarkan kriteria NCEP-ATP III, didapatkan proporsi sindroma metabolik pada subjek penelitian adalah 3 orang dari total 72 peserta. Sehingga jika dilakukan analisis 
statistik, didapatkan nilai $\mathrm{p}=1,75>0,05$. Hal ini menunjukkan bahwa penelitian ini tidak memiliki hubungan yang signifikan. Berdasarkan penelitian Sugondo pada tahun 2009, disebutkan bahwa indeks massa tubuh sangat berkaitan dengan sindroma metabolik karena persebaran lemak tubuh. ${ }^{9}$ Besarnya persebaran lemak sagat berkaitan dengan tingkat morbiditas dan mortalitas di berbagai populasi. $^{10}$

Dalam penelitian Fitria pada tahun 2014, lingkar perut menduduki posisi tertinggi sebagai penanda sindroma metabolik, yaitu sebesar $84,75 \%, \quad$ diikuti oleh hipertrigiseridemia $(49,15 \%)$, kadar HDL yang rendah $(44,07 \%)$, hipertensi $(38,98 \%)$ serta kadar gula darah puasa tinggi $(33,90 \%) .{ }^{11}$ Penelitian pada kelompok siswa SMP di Semarang dengan jumlah 116 siswa menunjukkan adanya sindroma metabolik pada kelompok obesitas sebesar 31,6\%, namun tidak didapatkan sindroma metabolik pada siswa dengan gizi normal. ${ }^{12}$

Sedangkan pada penelitian dengan total responden lanjut usia sebesar 489 orang, disebutkan bahwa berat badan berlebih memiliki risiko sindroma metabolik 4 kali lebih besar dibandingkan indeks massa tubuh normal. ${ }^{13}$ Hal ini diperkuat oleh penelitian Yao He dkk. pada tahun 2007, yang melakukan penelitian pada 2334 subjek lanjut usia di Cina. Subjek dengan BMI $\geq 25 \mathrm{~kg} / \mathrm{m}^{2}$ sangat berkaitan dengan sindroma metabolik hingga akhirnya meningkatkan risiko CHD (coronary heart disease), stroke, PAD (peripheral arterial disease). ${ }^{14}$

Indeks massa tubuh berfungsi untuk mengukur adiposa tubuh secara keseluruhan, sedangkan lingkar pinggang merupakan penanda dari obesitas sentral. Penelitian oleh Eckel dkk menunjukkan adanya keterkaitan antara sindroma metabolik dengan IMT, namun tidak dapat diperkirakan dengan lingkar pinggang. ${ }^{15}$ Suatu penelitian cross sectional di Syria dengan 2064 sampel yang berusia antara 18-19 tahun, dilakukan untuk menguji nilai prediksi BMI terhadap sindroma metabolik. Hasil penelitian tersebut menunjukkan adanya korelasi kuat antara kelebihan berat badan atau obesitas yang dinilai dengan BMI dan kompone-komponen sindroma metabolik (tekanan darah, gula darah puasa, trigliserida, kolesterol, LDLc dan Tg/HDL). ${ }^{16}$

\section{SIMPULAN DAN SARAN}

\section{Simpulan}

Hasil penelitian ini adalah tidak signifikan, yaitu tidak didapatkan hubungan antara BMI dan sindroma metabolik. Banyak penelitian menyebutkan bahwa terdapat korelasi yang kuat antara BMI dengan komponen-komponen sindroma metabolik seperti pengukuran tensi darah, gula darah acak ataupun gula darah puasa, kadar kolesterol, serta lingkar pinggang. Sehingga dapat disimpulkan bahwa BMI memiliki nilai 
prediksi terhadap terjadinya perubahanperubahan abnormal yang mengarah ke metabolik sindrom.

\section{Saran}

Dalam penelitian ini terdapat beberapa keterbatasan, yaitu jumlah sampel yang sedikit, kurangnya elemen sindroma metabolik yang diukur dan keterbatasan dana. Sehingga hasil penelitian menjadi tidak signifikan.

\section{REFERENSI}

1. Widjaya A. Obesitas dan Sindrom Metabolik. Forum Diagnosticum. 4:1-16 3. 2004.

2. Khan R, Buse J, Ferrannini E, Stern M. The metabolic Syndrome: Time for a Critical Appraisal: Join Statement from the American Diabetes Association and the European Association for the Study of Diabetes. Diabetes Care 2005; 28: 22892304. 2005.

3. Adult Treatment Panel III. Expert Panel on Detection, Evaluation, and Treatment of High Blood Cholesterol in Adults. Executive Summary of the Third Report of the National Cholesterol Education Program (NCEP) Expert Panel on Detection, Evaluation, and Treatment of High Blood Cholesterol in Adults (Adult Treatment Panel III). Journal American Medical Association. 285(16): 2486-96. 2001.

4. Aguilar M, Bhuket $\mathrm{T}$, Torres $\mathrm{S}$. Prevalence of the metabolic syndrome in the United States, 2003-2012. JAMA. 313: 1973-1974. 2015.

5. Koski L. Association of Body Amiss Index and Obesity with Physical Activity, Food Choices, Alcohol Intake, and Smoking In The 1982-1997 Fin risk Studies. American Journal of Clinical Nutrition; 75, 809-17. 2002.
6. Camhi SM, Evans EW, Hayman LL, Lichtenstein AH, Must A. Healty eating index and metaboliccallity healthy obesity in U.S. adolescents and adults. Prev Med; 77:23. 2015

7. Murti B. Prinsip dan Metode Riset Epidemiologi. Gadjah Mada University Press, Yogyakarta. 2003.

8. Siagian S.P. Manajemen Sumber Daya Manusia. Jakarta: Bumi Aksara. 2010.

9. Sugondo S. Buku Ajar Ilmu Penyakit Dalam Jilid III Edisi V. Jakarta: FKUI, hal 1977-1980. 2009.

10. World Health Organization, Expert Consultation. Appropriate Body Mass Index for Asian Populations and its Implication for Policy and Intervention Strategies. Lancet. 363:157-63. 2004.

11. Nurjanah, F. Gaya Hidup dan Kejadian Sindroma Metabolik pada Karyawan Laki-laki Berstatus Gizi Obesitas di PT. Indocement Citeureu. 2014.

12. Mexitalia, M. Sindroma Metabolik pada Remaja Obesitas. M Med Indonesia volume 43 No. 6 Tahun 2009. Pp 300. 2009.

13. Kamso, S. Body Mass Index, Total Cholesterol, and Ratio Total to HDL Chlesterol were Determinants of Metabolic Syndrome in the Indonesian Elderly. Med J Indonesia vol 16, No. 3, July-September 2007. P 195. 2007.

14. He, Yao. BMI Versus the Metabolic Syndrome in Relation to Cardiovascular Risk in Elderly Chinese Individuals. Diabetes Care 30:2128-2134, 2007. 2007.

15. Eckel R.H., Grundy S.M., and Zimmet P.Z.: The metabolic syndrome. Lancet; 365: pp.1415-1428. 2005.

16. Al Bachir, Mahfouz dan Mohamad Adel Bakir. Predictive Value of Body Mass Index to Metabolic Syndrome Risk Factor in Syrian Adolscent. Journal of Medical Case Report. 2017. 